\title{
Convalescent plasma to treat critically ill patients with COVID-19: framing the need for randomised clinical trials
}

\author{
Manu Shankar-Hari ${ }^{1,2^{*}}$ (D), Lise Estcourt ${ }^{3,4}$, Heli Harvala ${ }^{5,6}$, David Roberts ${ }^{3,4}$, David K. Menon, On behalf of the \\ United Kingdom SARS-CoV-2 Convalescent Plasma Evaluation (SCOPE) Consortium
}

We are in a severe acute respiratory distress syndrome coronavirus 2 (SARS-CoV-2) pandemic, causing coronavirus disease (COVID-19). SARS-CoV-2 is an enveloped RNA virus with cell entry facilitated by spike (S) protein that has a cleavage site at the S1-S2 boundary and other structural proteins such as membrane $(\mathrm{M})$, envelope (E), and nucleocapsid $(\mathrm{N})$ proteins [1]. Currently, there are two lineages of SARS-CoV-2 virus infecting humans, with similar virulence and clinical outcomes, derived from a common ancestor that originated in December 2019 in Wuhan $[1,2]$. Most patients who recover from SARS-CoV-2 illness will develop antibodies and memory lymphocytes against these proteins, which gives them immunity [3]. In this editorial, we discuss the biological, operational, and methodological questions that arise when designing a randomised controlled trial (RCT) of convalescent plasma in COVID-19.

\section{What is convalescent plasma therapy?}

Convalescent plasma refers to acellular plasma fraction of blood, containing antibodies against SARS-CoV-2 antigens, with virus neutralisation properties, collected from patients who have recovered from SARS-CoV-2 infections. Passive immunisation with $\mathrm{ABO}$ blood group-compatible convalescent plasma will reduce viral burden as neutralising antibodies will binding to the viral spike protein to either prevent interaction with angiotensin-converting enzyme-2 receptor or block the conformational changes in spike

\footnotetext{
* Correspondence: manu.shankar-hari@kcl.ac.uk

'School of Immunology \& Microbial Sciences, Kings College London, 5th Floor, Southwark Wing, London SE1 9RT, UK

2Guy's and St Thomas' NHS Foundation Trust, ICU Support Offices, 1st Floor, East Wing, St Thomas' Hospital, London SE1 7EH, UK

Full list of author information is available at the end of the article
}

protein preventing fusion to host cell membrane and provide immunomodulation.

\section{What do we know thus far about convalescent plasma therapy in COVID-19 illness?}

Since the recent Cochrane review that highlighted very low-certainty evidence on the effectiveness and safety of convalescent plasma in COVID-19 patients [4], Joyner and colleagues have reported safety results from a compassionate use convalescent plasma therapy programme in 5000 adults with COVID-19. They highlight that convalescent plasma is a safe treatment with an overall serious adverse event rate of $<1 \% \quad(n=$ 36 events), with TACO occuring in 7 patients, TRALI in 11 patients, and allergic transfusion reaction in 3 patients [5]. To date, one RCT has been published. This open-label trial stopped early after recruiting 103 of a planned 200 patients sample size were enrolled. The stoppage was due to low patient recruitment, as the pandemic abated in China, and importantly not for safety reasons [6]. The participants had either severe (respiratory distress and/or hypoxemia) or life-threatening (shock, organ failure, or requiring mechanical ventilation) COVID-19 illness. The intervention, ABOcompatible convalescent plasma at a dose of 4 to $13 \mathrm{ml} /$ $\mathrm{kg}$ of recipient body weight, and with an S-RBD-specific IgG titre of at least 1:640. The primary outcome was time to clinical improvement within 28 days, defined as patient discharged alive or reduction of 2 points on a 6point disease severity scale. The overall trial result was no statistically significant improvement in time to clinical improvement within 28 days between convalescent plasma with standard of care versus standard of 


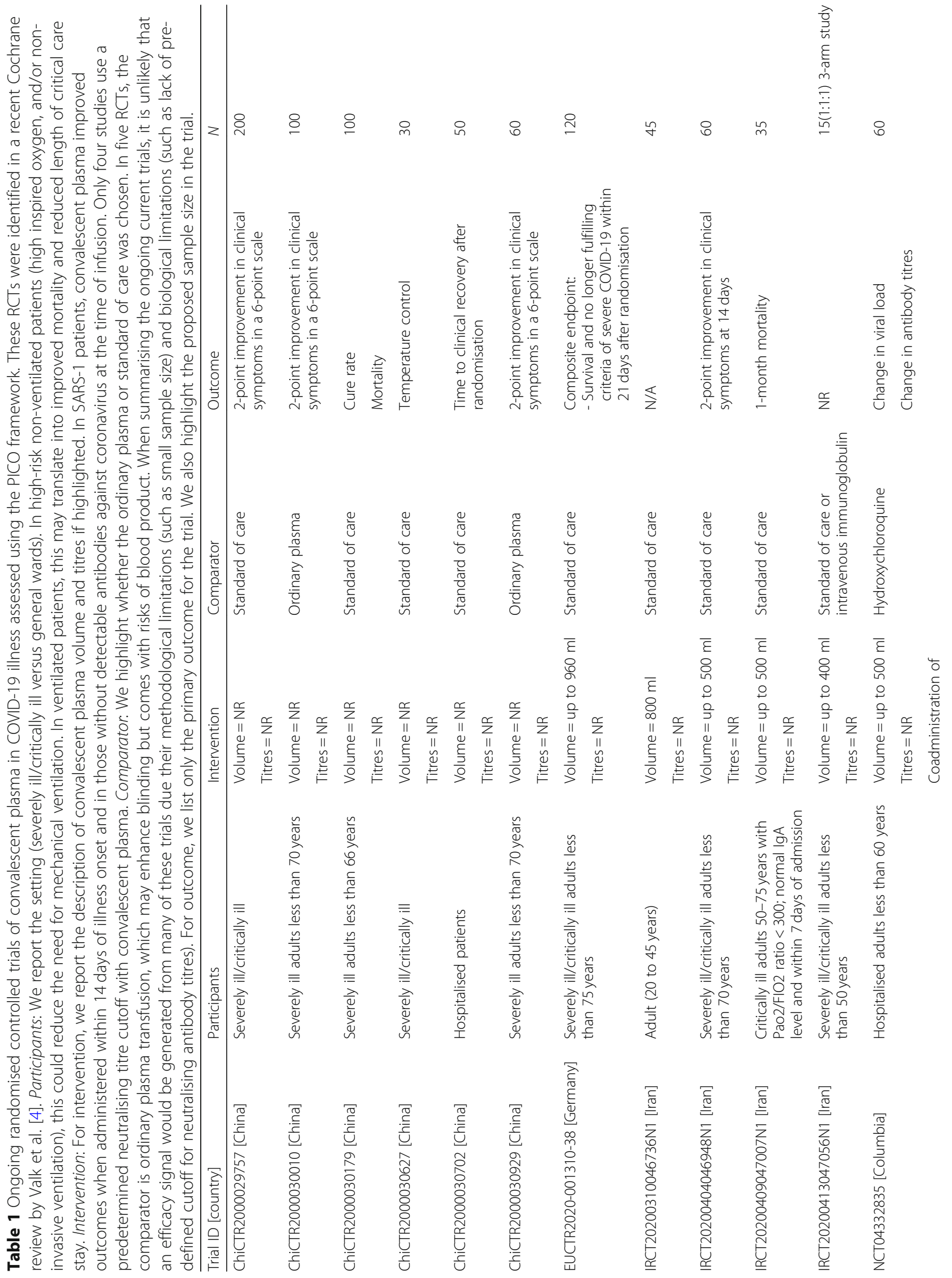




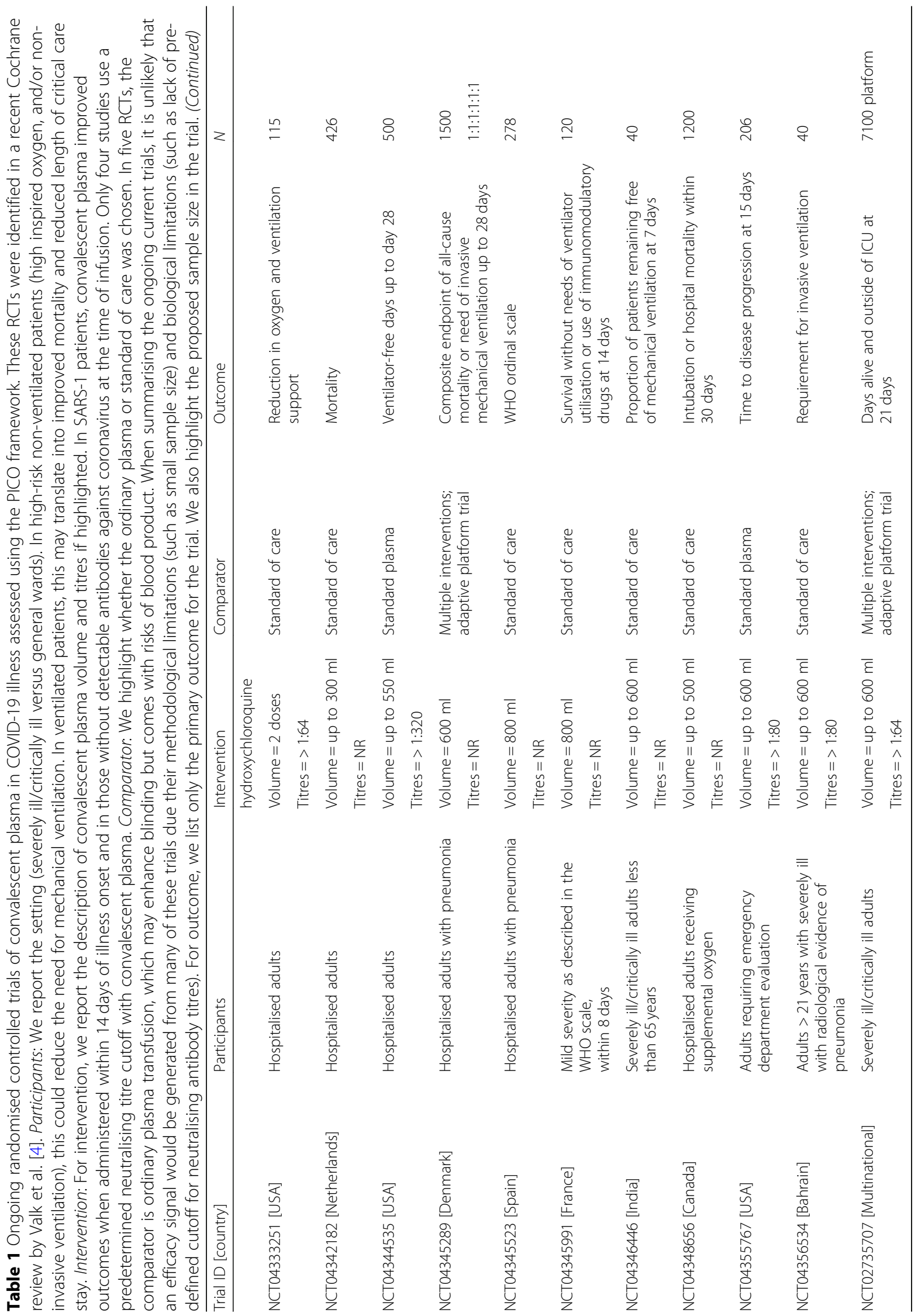


care alone. However, any inference from this trial is limited by it's early termination.

\section{Why do we need more RCTs of convalescent plasma?}

The risks of administering plasma screened for common blood-borne pathogens are small, but include allergy/ anaphylaxis, transfusion-related acute lung injury (TRALI), and transfusion-associated circulatory overload (TACO) [7]. TRALI and TACO are relevant as many COVID-19 patients have incipient respiratory failure that may worsen with convalescent plasma transfusion-related volume loading. Another specific concern with this intervention is antibody-dependent enhancement (ADE). In SARS-1 coronaviruses, $\mathrm{ADE}$ occurs by $\mathrm{S}$ protein neutralising antibodies enhancing viral entry into cells though fragment-crystallisable $(\mathrm{Fc})$ receptor expressing cells such as monocytes [8]. This has been shown to worsen lung injury in SARS-1 patients [9]. Non-randomised clinical use (compassionate) will not provide evidence of efficacy, which is an important consideration, as passive immunotherapy was ineffective in severe influenza A [10], and Ebola [11]. The impact of these harms would be difficult to identify outside a well-conducted RCT that collects adverse event data in a standardised way, whilst answering the efficacy question.

\section{Can we rapidly provide convalescent plasma with neutralising antibodies during a pandemic?}

Convalescent plasma can be collected safely from individuals who have recovered from laboratory-confirmed SARS-CoV-2 infection, as neutralising antibody responses begin by 14 days and continue to increase over the next few weeks. Currently, it is uncertain how long these antibodies persist, but in other coronavirus infections, neutralising antibodies may persist at high titres for at least 3 months before declining [12]. Therefore, collection of plasma around 28 days after recovery will provide an effective product with high titres of neutralising antibodies.

However, neither the method to assess viral neutralisation ability of convalescent plasma prior to administration nor the minimum titre of neutralising antibody that is required for treating critically ill patients with COVID-19 is known. There are two methods to assess viral neutralisation ability-pseudotype and live-virus assays. Pseudotype assays using harmless viruses that express the coronavirus spike protein, the target of neutralising antibodies, are a safer, easier, and more sensitive method for detecting neutralising antibody than livevirus assays that assess neutralisation of invasion of tissue culture cells by live virus [13]. The titres of antibody dose vary between studies, from $400 \mathrm{ml}$ of ABOcompatible convalescent plasma with neutralising antibody titre $>1: 40$ [14] to single $200 \mathrm{ml}$ dose of inactivated convalescent plasma with neutralising antibody titre $>1: 640[15]$.

\section{What are the key design issues to consider in RCTs of convalescent plasma?}

Current trials include participants with a range of COVID-19 illness spectrum, the intervention (convalescent plasma different timing, different doses, and need for molecular evidence of viral infection) and comparators are different, ranging from standard of care to use of regular plasma for blinding that adds transfusionrelated risks in comparator population, and outcomes differ between trials. It is conceivable that the treatment effect of convalescent plasma may differ by illness severity, by dose in terms of volume, concentration of neutralisation antibody, and the risk of ADE along with other adverse events during COVID-19 illness (Table 1) [4].

In summary, there is a clear biological framework for considering convalescent plasma as a potential intervention in COVID-19 illness. However, we need high-quality randomised controlled trials prior to using convalescent plasma as standard care in SARS-CoV-2 infections.

\section{Acknowledgements \\ Dr. Shankar-Hari is supported by the National Institute for Health Research (NIHR) Clinician Scientist Award (CS-2016-16-011). Prof. Menon is supported by an NIHR Senior Investigator award and through Cambridge NIHR Biomedical Research Centre funding. The views expressed in this publication are those of the author(s) and not necessarily those of the NHS, the National Institute for Health Research, or the Department of Health and Social Care. This manuscript is written on behalf of the United Kingdom SARS-CoV-2 Convalescent Plasma Evaluation (SCOPE) Consortium.}

\section{Authors' contributions}

MSH completed the first draft of the manuscript. LE, $H H, D R$, and DCM critically revised the manuscript for important intellectual content. All authors approved the final manuscript.

Funding

Not applicable.

Availability of data and materials

Not applicable.

Ethics approval and consent to participate

Not applicable.

Consent for publication

Not applicable.

Competing interests

All authors are involved in randomised clinical trials of convalescent plasma in the UK. No other competing interests declared.

\section{Author details}

'School of Immunology \& Microbial Sciences, Kings College London, 5th Floor, Southwark Wing, London SE1 9RT, UK. 'uy's and St Thomas' NHS Foundation Trust, ICU Support Offices, 1st Floor, East Wing, St Thomas' Hospital, London SE1 7EH, UK. ${ }^{3} \mathrm{NHS}$ Blood and Transplant, Level 2, John Radcliffe Hospital, Oxford OX3 9BQ, UK. ${ }^{4}$ Radcliffe Department of Medicine, University of Oxford, Oxford, UK. ${ }^{5}$ National Microbiology Services, NHS Blood and Transplant, Charcot Road, Colindale NW9 5BG, UK. ${ }^{6}$ Division of Infection 
and Immunity, University College of London, London WC1E 6JF, UK. 'Division of Anaesthesia, Department of Medicine, University of Cambridge, Box 93, Addenbrooke's Hospital, Cambridge CB2 ONUI, UK.

Received: 2 July 2020 Accepted: 9 July 2020

Published online: 20 July 2020

\section{References}

1. Andersen KG, Rambaut A, Lipkin WI, Holmes EC, Garry RF. The proximal origin of SARS-CoV-2. Nat Med. 2020;26(4):450-2.

2. Zhang X, Tan Y, Ling Y, Lu G, Liu F, Yi Z, Jia X, Wu M, Shi B, Xu S, et al. Viral and host factors related to the clinical outcome of COVID-19. Nature. 2020 https://www.nature.com/articles/s41586-020-2355-0.

3. Ni L, Ye F, Cheng ML, Feng Y, Deng YQ, Zhao H, Wei P, Ge J, Gou M, Li X, et al. Detection of SARS-CoV-2-specific humoral and cellular immunity in COVID-19 convalescent individuals. Immunity. 2020;52(6):971-7 e973.

4. Valk SJ, Piechotta V, Chai KL, Doree C, Monsef I, Wood EM, Lamikanra A, Kimber C, McQuilten Z, So-Osman C, et al. Convalescent plasma or hyperimmune immunoglobulin for people with COVID-19: a rapid review. Cochrane Database Syst Rev. 2020:5:CD013600.

5. Joyner MJ, Wright RS, Fairweather D, Senefeld JW, Bruno KA, Klassen SA, Carter RE, Klompas AM, Wiggins CC, Shepherd JR, et al. Early safety indicators of COVID-19 convalescent plasma in 5,000 patients. J Clin Invest. 2020. https:// www.nature.com/articles/s41586-020-2355-0.

6. Li L, Zhang W, Hu Y, Tong X, Zheng S, Yang J, Kong Y, Ren L, Wei Q, Mei H, et al. Effect of convalescent plasma therapy on time to clinical improvement in patients with severe and life-threatening COVID-19: a randomized clinical trial. JAMA. 2020. https://www.nature.com/articles/s415 86-020-2355-0

7. MacLennan S, Williamson LM. Risks of fresh frozen plasma and platelets. J Trauma. 2006;60(6 Suppl):S46-50.

8. Wan Y, Shang J, Sun S, Tai W, Chen J, Geng Q, He L, Chen Y, Wu J, Shi Z et al: Molecular mechanism for antibody-dependent enhancement of coronavirus entry. J Virol. 2020;94(5). https://pubmed.ncbi.nlm.nih.gov/31826 992/.

9. Liu L, Wei Q, Lin Q, Fang J, Wang H, Kwok H, Tang H, Nishiura K, Peng J, Tan Z et al: Anti-spike lgG causes severe acute lung injury by skewing macrophage responses during acute SARS-CoV infection. JCl insight. 2019;4(4). https:// pubmed.ncbi.nlm.nih.gov/31826992/.

10. Beigel JH, Aga E, Elie-Turenne MC, Cho J, Tebas P, Clark CL, Metcalf JP, Ozment C, Raviprakash K, Beeler J, et al. Anti-influenza immune plasma for the treatment of patients with severe influenza A: a randomised, doubleblind, phase 3 trial. Lancet Respir Med. 2019;7(11):941-50

11. Dodd LE, Follmann D, Proschan M, Wang J, Malvy D, van Griensven J, Ciglenecki I, Horby PW, Ansumana R, Jiang JF, et al. A meta-analysis of clinical studies conducted during the West Africa Ebola virus disease outbreak confirms the need for randomized control groups. Sci Transl Med. 2019:11(520):eaaw1049. https://www.nature.com/articles/s41586-020-2355-0.

12. Wu LP, Wang NC, Chang YH, Tian XY, Na DY, Zhang LY, Zheng L, Lan T, Wang LF, Liang GD. Duration of antibody responses after severe acute respiratory syndrome. Emerg Infect Dis. 2007;13(10):1562-4.

13. Temperton NJ, Chan PK, Simmons G, Zambon MC, Tedder RS, Takeuchi Y, Weiss RA. Longitudinally profiling neutralizing antibody response to SARS coronavirus with pseudotypes. Emerg Infect Dis. 2005;11(3):411-6.

14. Shen C, Wang Z, Zhao F, Yang Y, Li J, Yuan J, Wang F, Li D, Yang M, Xing L, et al. Treatment of 5 critically ill patients with COVID-19 with convalescent plasma. JAMA. 2020

15. Duan K, Liu B, Li C, Zhang H, Yu T, Qu J, Zhou M, Chen L, Meng S, Hu Y, et al. Effectiveness of convalescent plasma therapy in severe COVID-19 patients. Proc Natl Acad Sci U S A. 2020;117(17):9490-6.

\section{Publisher's Note}

Springer Nature remains neutral with regard to jurisdictional claims in published maps and institutional affiliations. 